\title{
Violência e realidade brasileira: civilização ou barbárie?
}

\author{
Eduardo C. B. Bittar
}

Universidade de São Paulo (USP)

\section{Violência e realidade brasileira: civilização ou barbárie?}

Resumo: Neste artigo, trata-se de compreender como, a partir dos estudos frankfurtianos, opera a vida no interior da sociedade moderna. Parte-se da discussão, pela crítica, do estado atual e da conjuntura brasileira de convivência com o fenômeno da violência que, além de alarmante, revela como o Estado de Direito não se consolidou. Essa situação cria um ciclo vicioso, pois é do seu não fechamento que se extrai a fonte de inúmeras injustiças e fenômenos de desigualdade e de violência que se encontram a corroer a solidariedade social em nossos tempos.

Palavras-chave: violência, sociedade, direitos humanos.

\section{Violence and the Brazilian Reality: Civilization or Barbarity?}

Abstract: This article uses Frankfurtian studies to analyze the operation of life within modern society. It is based on a critical discussion of the current state of the Brazilian situation of conviviality with the phenomenon of violence which, in addition to being alarming, reveals how the state of law has not been consolidated. This situation creates a vicious cycle, the lack this state of law allows countless injustices and phenomena of inequality and violence that corrode social solidarity.

Key words: violence, society, human rights. 
1 Violência e realidade brasileira: a barbárie nacional

A violência tem-se tornado um dos principais fatores de demonstração das insuficiências do Estado de Direito no momento atual, especialmente se considerada a realidade brasileira. Esta investigação não se deita sobre a pretensão de extrinsecar as causas da violência, e muito menos de apresentar um conceito rigoroso de violência, mas parte de algumas hipóteses e de algumas constatações. Os relatos e registros sãos os mais diversos e observam as peculiaridades regionais, todas elas suficientes para declarar algo das distorções existentes, que conferem ao tema da violência um colorido muito específico. O Brasil, com dados de 1999, com taxa de 26, 3\% homicídios por 100 mil habitantes, foi considerado em segundo lugar entre os 60 países mais violentos do mundo ${ }^{1}$. Trata-se de um quadro suficientemente aberrante para dizer algo daquilo que tem sido a realidade brasileira hodierna. A violência que entrecorta o Brasil é a mesma que afasta investidores, leva à morte milhares de vítimas, provoca o encarecimento de produtos e serviços segurados, fomenta injustiças sociais, determina políticas de segurança truculentas, constrói o medo social, legitima frentes de ação popular conservadoras, degenerando os laços da vida social $^{2}$.

É desta complexa trama de implicações que decorre a violência, instalando-se sob a pele do tecido social, inoculando em suas artérias e veias o veneno letal capaz de lhe corromper a essência, até a sua plena exaustão. É exatamente essa questão que vem afligindo não somente a reflexão acerca do assunto, mas também as próprias vidas de homens e mulheres, em qualquer condição social, econômica ou política, porque de fato dela ninguém está completamente isento ${ }^{3}$. Seu acirramento nas últimas décadas está sendo capaz de criar ondas de alarmismo no governo e na sociedade no sentido da criação de uma consciência da amplitude dos problemas que devem ser solucionados, não sendo raro que os diagnósticos e políticas públicas deságüem em caminhos e alternativas quase sempre incapazes de irem às raízes dos problemas e mazelas sociais. Questões ligadas a déficits de cidadania e igualdade, e cidadania aqui entendida como acesso a bens fundamentais da vida comum, são, normalmente, tratadas como questões de políticas de segurança públi- $\mathrm{ca}^{4}$. Nesse sentido, a violência se 'produz' e se 'reproduz' de modo circular, evidenciando que, se suas causas não são elaboradas e conscientizadas, perpetua-se de modo pernicioso na dinâmica de organização da vida social.

De fato, desde há algumas décadas, a violência deixou de ser considerada uma questão lateral na dinâmica da vida contemporânea, não podendo, muito menos, ser desprezada enquanto indício da dissolução social. Muito menos deve ser considerada um problema pontual, mas sim a decretação de um alarmante estado de instabilidade e descontentamento geral da sociedade, nos modos pelos quais gerencia os seus próprios problemas. Muito menos ainda pode ser considerada um problema isolado do contexto de um Estado ou de um país ${ }^{5}$.

No entanto, o ciclo de traumatizações sociais, que no caso brasileiro, remontam aos efeitos do escravismo $^{6}$, no lugar de se reduzir, tende a se ampliar, na medida em que a violência cria reações sociais, todas elas atemorizadas e que possuem tendências à repetição de ciclos de violência. Thánatos atrai Thánatos ${ }^{7}$. Dessa forma desenvolvem-se sentimentos e raciocínios sociais que, do ponto de vista da população atemorizada, acabam por ser as bases para a incrementação de reações truculentas e investidas autoritárias contra a própria sociedade, evidentemente, que, agora, como reações canalizadas para os setores sociais considerados responsáveis pelos temores coletivos, os mesmos setores desprestigiados pelas políticas públicas mais elementares ${ }^{8}$. Assim, os mesmos estereótipos sociais vão se repetir como vítimas do processo de perseguição, onde a culpa é depositada com o fervor mais intenso, quanto mais intenso for o clamor público e, geralmente isto se dá, com ações que atingem as populações das periferias dos grandes centros urbanos. A dilatação da busca social por segurança torna-se esquizofrênica, assim como a busca do culpado social, que leva à execração do criminoso, à reinvenção dos mitos higienistas sociais e ditatoriais, à retomada dos fundamentalismos sociais, tudo acompanhado do renascimento acalorado do debate sobre a necessidade da adoção da pena de morte. O espantoso crescimento da violência vem acompanhado por um, também espantoso, processo de concessão de poderes ilimitados à polícia, de violação de direitos humanos, de aumento das formas políticas de exceção e de autoritarismo social. 
Nessa medida, o que se percebe é que, a população acossada, diante das cotidianas violações que permanecem impunes, o Estado de Direito incapacitado de agir eficazmente na condução de políticas consistentes para atacar as causas das crescentes estatísticas de violência, a vida social se torna um verdadeiro jogo de trocas de culpas, em que sociedade civil e Estado saem ambos perdendo. Para além desta projeção circular de culpa, as tendências sadomasoquistas da sociedade individualista e de consumo deixam suas marcas na vida contemporânea. Isso porque, quanto maior a tendência à concentração do capitalismo financista, globalizado e excludente, maior o conjunto de efeitos negativos projetados para dentro da vida econômica e social. Tudo isso detona uma forma de visão de mundo altamente masoquista, ou seja, autoritária, porque passa a desejar o alívio do prazer (segurança, paz, justiça) a partir da aplicação da dor (tortura, pena de morte, linchamento) sobre o próprio corpo da sociedade civil $^{9}$. Isso faz com que a sociedade contemporânea se desenvolva como uma sociedade de caráter autoritário, dando claras demonstrações de recuo no plano dos direitos humanos. Por isso, as legitimadas e ostensivas demonstrações de crueldade e de violência exasperada são aparições de uma patologia social instalada no seio dos modos de organização da sociedade hodierna, que lembram, nas descrições freudianas, processos sadomasoquistas ${ }^{10}$. Isto, de novo, revela manifestações de Thánatos, mas agora de um Thánatos que toma posse de Éros ${ }^{11}$.

\section{Violência, criminalidade e atentado: o Estado de Direito em seu limite}

Para além das evidências imediatas do senso comum, a análise cobra a formulação necessária de um juízo lastreado no exercício de interpretação da sociedade contemporânea capaz de conduzir a melhor diagnosticar e compreender, no crescimento da violência e nos distúrbios sociais, processos que revelam 'significados sociais' nada desprezíveis. Trata-se de apreender pela superfície simbólica aquilo que estes signos valem para a decodificação de processos psicopatogênicos do ponto de vista social e o que significam do ponto de vista civilizacional para as sociedades contemporâneas. Trata-se de levar a sério a afirmação de Theodor Adorno (2002, p. 12): "A violência da sociedade industrial opera nos homens de uma vez por todas"12.

Quando se constatam processos sociais que inevitavelmente revelam na superfície dos fatos sociais a mecânica profunda da dialética do esclarecimento, o que se colhe é bem visível aos olhos, a saber, as múltiplas faces da violência: rebeliões carcerárias sangrentas que paralisam a vida social de diversos estados brasileiros; manifestações de poder da criminalidade organizada como ostensivas demonstrações de forças nas ruas das grandes cidades; chacinas em subúrbios promovidas por poderes paralelos ao Estado e sua legalidade; a formação de grupos de extermínio, exercendo a função de higienismo social; a multiplicação de milícias privadas, que recebem o acolhimento de membros corruptos das polícias e membros de bandos de criminosos e traficantes locais; o uso de técnicas de criminalidade e de crueldade crescentes, como têm se revelado em episódios recentes o esquartejamento na carceragem de membros de facções criminosas distintas, ou mesmo o caso de João Hélio no Rio de Janeiro; a perseguição a minorias de todos os tipos, como forma de endurecimento do trato relativo ao pluralismo social; o crescimento assustador de diversas formas de abuso sexual, exploração infantil e tráfico de menores para fins sexuais; a sofisticação da atrocidade, das formas de tratamento cruel e de atentados à dignidade humana ${ }^{13}$.

Trata-se de um conjunto de curto-circuitos que, se lidos isoladamente, nada significam, senão distúrbios ocasionais de integração social ou perturbações locais em setores específicos da vida social. Mas, no fundo, aqui, quer-se interpretar desta forma, trata-se da revelação de processos sociais que interrompem a normalidade do cotidiano para significarem que nem somente de luzes (Auflkärung) vive a modernidade. O Brasil contemporâneo torna-se, por isso, o claro retrato da dialética do esclarecimento e seus paradoxos. Afinal, seu dístico maior aparece em sua bandeira moderna e positivista como sendo 'ordem e progresso'. Nesta medida, a nação surgida das práticas mercantilistas e capitalistas modernas, torna-se, exatamente por isso, um fruto claro do espírito contraditório da modernidade. E isso porque a modernidade promete esclarecimento e pratica ideologia, promete riqueza e produz pobreza, promete justiça e realiza desequilíbrios sociais crescentes, promete luzes e realiza opressão. A face da modernidade realizada, como verificam os frankfurtianos de primeira geração, tem pouco a ver com o espírito do iluminismo humanista e muito a ver com a forma de realização e concretização da razão instrumental ${ }^{14}$.

Nesta medida, as sociedades contemporâneas passam a se conduzir na base de uma lógica muito específica, a saber, a lógica do atentado. $\mathrm{O}$ 'regime do atentado' é incorporado ao dia-a-dia e se traduz nesta sempre presente mecânica em que susto, medo, repulsa, defesa, choque, ataque, intolerância, contraataque, sobrevivência, luta, estratégia, golpe ${ }^{15}$ se tornam termos corriqueiros, parte desta gramática do cotidiano $^{16}$. De um lado, indivíduos socializados que são convidados ao 'salve-se quem puder' 17 , de outro lado, uma sociedade mecanizada por uma estilística de vida fundada no princípio inquebrantável do progresso em direção ao futuro. Isso explica um caráter 
autoritário disperso na atmosfera cultural contemporânea que se esparge pelo convívio através de ações de repulsa e de supressão do outro (de sua presença corpórea, de sua identidade, de sua personalidade, de seu simbolismo, de sua liberdade, de sua capacidade financeira...). O corpo se tornou redundante, por isso é vitimizado, atacado, violentado, suprimido.

Instruída por essa mecânica, na sociedade moderna do capitalismo avançado e globalizado, o espaço do comum é transformado em 'campo de batalha', senão a 'suave' batalha do mercado (loosers/ winers), a construção do ringue que opõe violentadores e violentados. O cidadão comum e normal é visto como um partícipe deste estado de natureza hobbesiano instalado no interior da sociedade contemporânea ${ }^{18}$. Uma sociedade fomentada ao exercício desta forma de entendimento humano é uma sociedade do medo, da insegurança, da desconfiança, e, por isso, necessariamente instável, injusta, e, reativamente, violenta. $\mathrm{O}$ medo, sentimento fundamental para a sobrevivência, sentimento até mesmo autoprotetivo do indivíduo, torna-se a linguagem da desidentificação a corroer a solidariedade social. A surpresa latente do susto, sempre em suspensão na atmosfera é um elemento de acirramento das tensões e tendências violentas, das criadoras de violências às reativas à violência inflingida ${ }^{19}$. A imagem que se tem das sociedades contemporâneas, principalmente das mais desenvolvidas e em seus centros urbanos, é a de sociedades que convidam seus membros a um retorno à selvageria e à sobrevivência na floresta como habitat natural. Passa-se a ter a metáfora da selva, do instinto, da predação, da sauvagerie, no coração pulsante da civilização. É deste paradoxo que se trata de extrair o que se processa com a modernidade. Este cenário insculpe uma psyché social: de um lado, assustada, fundada na crença em soluções finais e conservadoras; de outro lado, assustadora, fundada na crença no golpe como forma de violentar pela violência sofrida (truculenta) ${ }^{20}$.

Eis a feição de uma sociedade profundamente contraditória. Trata-se de uma sociedade que experimenta oposições, clivagens e diferenças. A natureza traumática de nosso tempo decorre desse conjunto de outros eventos que vêm marcando a psyché social nas últimas décadas. A gestação de uma nova forma psíquica no interior da sociedade moderna é mesmo o resultado deste trauma-maior, Auschwitz, no seio da civilização ${ }^{21}$. Por isso, ordem e desordem estão intercaladas. Civilização e barbárie se ladeiam. Pulsão de vida e pulsão de morte se mesclam. Eclipses episódicos, portanto, estão previstos no intercurso da história que se orienta desta forma e segundo estas fórmulas que incrementam Thánatos.

A ausência sistemática do Estado pode ser apontada como um dos grandes fatores a consentir com o estado atual da violência, mas certamente não é a causa histórica de todos esses processos de injustiça social. Desta ausência se nutre, sem dúvida alguma, uma série de atitudes de contraste, que falam a linguagem do crime organizado, da aparição de redes intra e extracarcerárias de solidariedade, apontando para a formação de lideranças que não aquelas que confirmam a autoridade do Estado de Direito. Em meio a isto tudo, estão os grandes problemas hodiernos, que são revelações da opressão social: sensações individuais de insatisfação não compensada; afrouxamento das estruturas sociais e crescimento da impunidade; maus-exemplos das lideranças políticas através da corrupção; injustiça e clivagens sociais; inexistência de lugar para o discurso oprimido; falta de alternativas paradigmáticas no horizonte próximo; complexidade dos fatores sociais contemporâneos.

Os nossos tempos tornaram o princípio de realidade especificamente mortífero (a frustração da civilização; a ausência de alternativas; a morte das utopias; o fim das metanarrativas), na medida em que os nossos tempos se fazem avessos a quaisquer sentimentos de solidariedade, e fazem com que se dissolva no plano do individualismo toda tentativa de mudança social ${ }^{22}$. São estes fatores que tornam o impulso libidinal rebelde, ou seja, torna o impulso libidinal anticivilizatório, empurrando-o para a latrina da pulsão de morte, convertendo-o em nervosismo da civilização contra si mesma, cujo sintoma é a violência, a intolerância, o ataque, a sabotagem, a crueldade. A frustração social permanente conduz a um movimento anticivilizatório, que escancara e torna cínica a violência, na medida em que assume a regularidade do cotidiano, e não a espantosa configuração da surpresa, e em que é assumida como um fator de normalidade na composição do jogo social, mesmo do jogo social reivindicativo e emancipatório.

A idéia de uma sociedade não-repressiva parece não ser tão inatingível ou inviável quanto parece ser à primeira vista, e isto no interior do próprio pensamento freudiano ${ }^{23}$. No entanto, se as promessas da sociedade moderna giravam em torno de liberdade, igualdade e fraternidade, o que se tem, hodiernamente, é uma sociedade mais controladora (que seduz pela mídia em direção ao ter), e, por isso, mais castradora do despossuído (aquele que não tem o poder de compra):

\footnotetext{
A ideologia hodierna reside em que a produção e o consumo reproduzem e justificam a dominação. Mas o seu caráter ideológico não altera o fato de que os seus benefícios são reais. A repressividade do todo reside em alto grau na sua eficácia: amplia as perspectivas da cultura material, facilita a obtenção das necessidades da vida, torna o conforto e o luxo mais baratos, atrai áreas cada vez mais vastas para a órbita da indústria - enquanto, ao mesmo tempo, apóia e encoraja a labuta e a destruição. O indiví-
} 
duo paga com sacrifício do seu tempo, de sua consciência, de seus sonhos; a civilização paga com sacrifício de suas próprias promessas de liberdade, justiça e paz para todos (MARCUSE, 1999, p. 99).

Esses traços que constituem epicentros do processo de geração de desigualdade e violência, que culminam nas atitudes controladoras do Estado, na tentativa de evitar o desarranjo social, e as conseqüências são todas elas repressoras e não-libidinais: aumento das penas; recrudecimento do sistema carcerário; cassação de direitos e garantias constitucionais; aumento de práticas truculentas de segurança pública; aumento do poder de exceção do Estado na gestão de políticas políticas de segurança ${ }^{24}$.

\section{Estado de Direito: a conversão da linguagem do direito na linguagem da violência}

A clássica imagem do brasileiro que se fundava no exemplo da cordialidade se torna mais e mais uma evocação de um passado empalidecido por uma realidade inóspita. "Já se disse, numa expressão feliz, que a contribuição brasileira para a civilização será a cordialidade - daremos ao mundo o "homem cordial", afirma Sergio Buarque de Holanda (2006). Verificar se este traço persevera na caracterização do brasileiro carece, antes de tudo, de que se saiba o que é cordialidade. A cordialidade, como traço de um caráter hospitaleiro, talvez seja algo notável do povo brasileiro, de fato. Esta é uma forma de cordialidade, bem apreciada geralmente pelos estrangeiros. Mas, existe uma outra forma de se expressar cordialidade no trato com o outro, e esta outra idéia remete à consideração do outro pelo que se constrói de comum na vida compartilhada. Sabendo que o outro depende tanto quanto eu do que é institucional e comum, ser cordial significa contribuir para o fortalecimento das instituições públicas.

Então, se cordialidade for o respeito às instituições que dão substrato para o equilíbrio da vida em comum, da vida social, a resposta ao dilema institucional brasileiro é certamente encaminhada para dentro da história de formação do publicismo privatista brasileiro. O Estado de Direito sempre teve severas dificuldades de se afirmar com independência e autonomia na realidade histórica brasileira, sem que isso representasse a necessidade de alianças e conchavos políticos com os donos do poder. Assim, parece estar enraizada na dimensão da cultura um decreto que tem força de lei em nosso meio social, e que se exprime da seguinte forma: "Quem for mais esperto, terá mais chances de se dar bem neste país." Daí, deriva o imperativo categórico que lhe é subseqüente: "Sê esperto, e faz do teu comportamento a base de teu próprio benefício." Sem contar que este impe- rativo cultural brasileiro inverte o imperativo moral que remonta ao pensamento de Kant, como expresso na Crítica da razão prática, que exige o compromisso de cada um com todos ("Age de tal modo que a máxima da tua vontade possa valer sempre ao mesmo tempo como princípio de uma legislação universal"), elemento este que serve de base para a ética e para a cidadania, ele é o caminho rápido e rasteiro para a dissolução da vida pública e compartilhada. É o famoso jeitinho. "Mas o uso do ‘jeitinho’ e do 'sabe com quem você está falando?'. Acaba por engendrar um fenômeno muito conhecido e generalizado entre nós: a total desconfiança em relação a regras e decretos universalizantes", como afirma Damatta (1997, p. 238)

Quando um se arroga na condição de quem se torna o beneficiário (e nunca o devedor) máximo de tudo e, simultaneamente, age de modo a instrumentalizar tudo e todos em nome de seus interesses pessoais, não há justiça possível. A modernidade do fare l'America ainda vale entre nós; por isso, não lutamos por algo que seja comum, mas somente por um 'se dar bem, e regressar ao país de origem'. Nesse percurso, muitos se deram bem, outros nem tanto, muitos sequer regressaram ao país de origem, mas a lógica ficou. E isto haverá de se refletir em todos os extratos sociais e de muitas formas. Talvez tudo isso faça parte de um imaginário social formado a partir da originária forma de colonização portuguesa expoliatória adotada na colônia (para onde pouco se leva e de onde tudo se traz), mas já é tempo de, proclamada a independência, revisarmos nossos valores.

Por isso, o que se constata é que não há nada de cordial no homem brasileiro se for considerado que, no período de 1980 a 2005, tenham ocorrido, em São Paulo, 7.659 casos de execução sumária pela polícia, que se registrem 1.329 casos de estupro, somente em 2003, no Rio Grande do Sul, ou de que, em 2003, se registrem $16,4 \%$ das crianças, entre 10 a 14 anos, ligadas ao trabalho infantil no Pará, ou que, no Mato Grosso, as denúncias de exploração sexual de crianças e adolescentes alcancem taxas de 7,25 denúncias por 100 mil habitantes, no período de 2003 a 2005, ou ainda, que, em 2003, 169 conflitos de terra tenham envolvido 92.390 pessoas, resultando em 12 mortes no estado de Pernambuco, como registram os dados do Terceiro Relatório Nacional sobre os Direitos Humanos no Brasil, do Núcleo de Estudos da Violência (NEV-USP) (UNIVERSIDADE DE SÃO PAULO, 2007).

Neste contexto, portanto, o Estado de Direito dá claras demonstrações de incapacidade de reação, ante um quadro gigantesco e alarmante de crise so$\mathrm{cial}^{25}$. Vê-se, neste sentido, envolvido num círculo de ação e reação, em que sua legitimidade se torna ainda mais confiscada. Muitas vezes, ele luta contra 
aquilo que ele mesmo tem provocado, através de políticas desacertadas e complicações burocráticas ${ }^{26}$. Sem uma cultura do que é público, e obedecendo, ou até aprofundando a lógica que já havia fundado a identidade desigual brasileira, as alternativas são parcas de elevar o debate em direção a qualquer tipo de perspectiva ${ }^{27}$. Nesta medida, o Estado de Direito, que se encontra na curvatura histórica, entre civilização e barbárie, administra os efeitos de um processo de liquidação de sua própria legitimidade conquistada historicamente no albor da modernidade ${ }^{28}$. Exatamente por isso, vê-se ameaçado. A violência nada mais significa do que a retomada do poder em outra linguagem, que não a da razão, em tempos em que a dissolução do Estado compromete a organização corporativa da vida social $^{29}$.

Nenhum tipo de solução pode ser entrevisto no horizonte, se a resposta que se aguarda depender das leis do mercado, ou se a resposta for procurada na intensificação da criminalização social (inclusive dos movimentos sociais), na manutenção da dicotomia que separa sociedade civil de Estado e torna a cidadania uma expectativa passiva dentro da representatividade política, ou no quietismo alarmante que silencia e compactua sem mobilização consistente ante o cataclisma social. Qualquer resposta que possa apontar perspectivas passa, necessariamente, por incentivos à cidadania, à participação, à inclusão política e econômica, assim como pela ampliação da democracia e reforço do papel prestativo do Estado, pelo fomento de uma cultura pluralista, tolerante, democrática e centrada nos direitos humanos.

Isto porque se entende que onde a violência ocupou o lugar do discurso, e onde a irracionalidade se apresenta como única racionalidade possível, então, de fato, estão presentes os elementos de uma sociedade dominada por Thánatos. A violência é o avesso do discurso, é o avesso do entendimento ${ }^{30}$. É a supressão do outro e da racionalidade, da integração e da solidariedade. A violência degenera a comunicação, cessa a reciprocidade, degrada a dignidade do outro, assim como consente o aplauso a um modo de interação que desprivilegia a aceitação do outro como um igual numa interação comunicativa, para proscrever o lugar do outro em favor da lei da força ${ }^{31}$. O compromisso moral em sociedade é o compromisso da manutenção de uma interação fundada em mecanismos de evitação da degradação das interações ou de promoção de formas de encaminhamento de conflitos (punitivos ou conciliatórios) que sejam capazes de traduzir a sensação fundamental de que o pacto do convívio social não se rompe, mesmo sob a constante ameaça de atos de injustiça e violência. No entanto, a retomada em escala progressiva da violência tem feito com que se coloque em dúvida o fato de que se vive efetivamente em civilização.

Nesta linha de raciocínio, entende-se que o espaço do discurso, que vem sendo suprimido, é o espaço do gozo intersubjetivo, da comunhão, da explosão de vida em conjunto. A negação do espaço do discurso é a afirmação do princípio de morte. São necessários, exatamente por isso, mecanismos de incentivos a Éros - considerando-se tratar não de um Éros desequilibrado, este que é tão inconseqüente e irresponsável quanto Thánatos ${ }^{32}$ - são de todo necessários em nossos tempos, através de iniciativas as mais variadas para o atendimento à dignidade humana. A partir daí se pode começar a pensar na formação de uma sociedade mais equilibrada. Se Éros não for valorizado, a tendência de seu eclipse é uma natural decorrência do acalento de Thánatos, na linha das preocupações marcuseanas em torno do texto freudiano:

\section{A cultura exige sublimação contínua; por conseguin- te, debilita Eros, o construtor de cultura. E a dessexualização, ao enfraquecer Eros, liberta os im- pulsos destrutivos. Assim, a civilização é ameaçada por uma difusão instintiva, em que o instinto de morte luta por ganhar ascendência sobre os instintos de vida. Originada na renúncia, a civilização tende para a autodestruição (MARCUSE, 1999, p. 87).}

O que se vive hodiernamente, portanto, por esse conjunto de sintomas sociais, é uma ameaça à sobrevivência da cultura dos direitos, na medida em que, como afirma Agamben, baseado em Benjamin, o que

[...] o direito não pode tolerar de modo algum, o que sente como uma ameaça contra a qual é impossível transigir, é a existência de uma violência fora do direito; não porque os fins de tal violência sejam incompatíveis com o direito, mas pelo simples fato de sua existência fora do direito (BENJAMIN, 1921, p. 183 apud AGAMBEN, 2004, p. 85).

\section{Conclusões}

Compreende-se que, a partir da análise trazida por este estudo, o problema da escalada da violência 
se apresenta como conseqüência de uma mecânica social específica, aquela construída e fundada na lógica ambivalente da modernidade. Desta forma, é que nosso tempo se torna uma sucessiva onda de manifestações de violência, atentados, carnificinas, genocídios, guerras e eventos macabros, que tornam a assinatura deste tempo muito mais afim com a dimensão de Thánatos do que de Éros ${ }^{33}$. Quando Thánatos ecoa em nosso tempo, a condição hodierna se vê marcada pela indelével marca da ressonância do medo, do temor, da violência, do trauma psicossocial, de cujas ondulações não se pode libertar os indivíduos do hoje $\mathrm{e}^{34}$. Suas ressonâncias tornam inaudíveis as vozes que falam a favor de Éros.

Trata-se de um conjunto de relações que associam a técnica e o saber ao poder e ao interesse econômico, e que fundam conseqüências traumáticas que demarcam espaços históricos, campos, que repercutem efeitos projetados para o futuro. São esses efeitos absolutamente conectados a processos de liberação de forças instintivas, que incrementam trocas dessimbolizantes, demarcatórias de relações de pura força, e, portanto de instinto de morte. São esses elementos que, se tornando ingredientes banais do cotidiano, incrementam formas dissolutórias dos processos de integração comunicativa, com conseqüências danosas à solidariedade integrativa.

Por isso, a violência é interpretada não como um fenômeno que destoa da vida moderna, mas que realiza a própria dialética que se encontra interiorizada em seu funcionamento. A exceção é, por isso, feita regra, e, desta forma, a violência se banaliza para se tornar um mecanismo de adaptação do convívio social hodierno. A questão que sobra nos expõe a perguntar-nos: como ficam os direitos humanos nesta conjuntura? As lesões sistemáticas aos direitos humanos são tornadas parte desse processo de adaptação, e, exatamente por isso, os direitos humanos acabam por representar uma linguagem que, apesar de assente nos debates políticos, filosóficos e sociais há mais de 250 anos, parece sempre ser nova, e carente, inclusive, de assentimento popular para se sustentar, na medida em que forças sadomasoquistas e autoritárias passam a determinar a linguagem de reação que reconduz a novos ciclos de terror e violência. Eis a equação de um tempo.

\section{Referências}

ADORNO, Sérgio. Os aprendizes do poder: o bacharelismo liberal na política brasileira. São Paulo: Paz e Terra, 1988.

. Contemporaneidade, poder e novos ilegalismos. Direito e perspectivas jurídicas, Revista dos Anais do I Congresso de Iniciação Científica da Faculdade de Direito da Universidade de São Paulo, São Paulo, C.A. XI de Agosto/FAPESP, 1, p. 137-147, 1996.
ADORNO, Sérgio. Crime, justiça penal e desigualdade jurídica. In: SOUTO, C.; FALCÃO, J. (Org.). Sociologia e Direito, São Paulo: Pioneira,1999, p. 316.

. Um país que se tornou refém da impunidade. $O$ Globo, Rio de Janeiro; São Paulo, Especial 3, Domingo, 22 set., 2002. Entrevista

. Crime, punição e prisões no Brasil: um retrato sem retoques. In: FORO IBEROAMERICANO SOBRE SEGURIDAD CIUDADANA, VIOLÊNCIA SOCIAL Y POLÍTICAS PUBLICAS, Madrid, Espanha. Anais..., junho 2006, p.19-21. No prelo.

.; MESQUITA, M. Direitos humanos para crianças e adolescentes: o que há para comemorar?In:AMARAL JÚNIOR, A. do; PERRONE-MOISÉS, C. (Org.). O cinqüentenário da Declaração Universal dos Direitos do Homem. São Paulo: Editora da Universidade de São Paulo, 1999, p. 265-289.

ADORNO, Theodor W. A indústria cultural e sociedade. Tradução de Júlia Elisabeth Levy et al. São Paulo: Paz e Terra, 2002.

AGAMBEN, G. Estado de exceção. Tradução de Iraci D. Poleti. São Paulo: Boitempo, 2004.

ALMEIDA, G. A. de. Direitos humanos e não-violência. São Paulo: Atlas, 2001.

BARRETO, V. Educação e violência: reflexões preliminares. Revista Brasileira de Filosofia, São Paulo, v. XXX, fasc. 165, jan.-mar. 1992, p. 63-70.

BITTAR, E. C. B. O direito na pós-modernidade. Rio de Janeiro: Forense Universitária, 2005.

BOHLEBER, W. Trauma extremo, o colapso da civilização e as conseqüências de longo prazo para indivíduos e sociedades. IDE, Sociedade Brasileira de Psicanálise, v. 1, n. 1, p. 112-118, 2005.

CAMPOS, A. et al. Atlas da exclusão social no Brasil: dinâmica e manifestação territorial. São Paulo: Cortez, 2003. (v. 2).

CARDIA, N. Punishing the Victims: the Paradox from Failing to Repair. In: SYMPOSIUM IV: The Smbivalence of Social Change, in 15th World Congress of Sociology, Brisbane, Australia, 2002. Disponível em: <http://www.nevusp.org >. Acesso em: 18 jun. 2007.

. Os impactos da exposição à violência ou horror continuado? O caso de São Paulo. In: CULTURE, CYTIZENSHIP AND URBAN VIOLENCE SEMINARY, Cuernavaca, México, 1999. Disponível em: <http:// www.nevusp.org>. Acesso em: 18 jun. 2007. 
CARVALHO, G. S. de. Um breve panorama da teoria sobre a violência criminal urbana no Brasil. Revista Brasileira de Ciências Criminais, São Paulo, ano 7, n. 27, p. 309-326, jul.-set.1999.

MATTA, R da. Carnavais, malandros e heróis: para uma sociologia do dilema brasileiro. Rio de Janeiro: Rocco, 1997.

ENDO, P. C. A violência no coração da cidade: um estudo psicanalítico sobre as violências na cidade de São Paulo. São Paulo: Escuta/Fapesp, 2005.

FREUD, S. O mal-estar na civilização. Tradução de José Octávio de Aguiar Abreu. Rio de Janeiro: Imago, 1997.

. Além do princípio de prazer. Obras completas, v. XVIII, p. 17-75, Rio de Janeiro: Imago, 1999.

FROMM, E. Ter ou ser? Tradução de Nathanael C. Caixeiro. São Paulo: LTC, 1987.

HERMANN, F. Psicanálise e política: no mundo em que vivemos. Percurso, Revista de Psicanálise, ano XVIII, n. 36, p. 5-25, 2006.

HOLANDA, S. B. de. Raízes do Brasil. Edição Comemorativa. São Paulo: Companhia das Letras, 2006.

HORKHEIMER, M. Crítica de la razón instrumental. Traducción de Jacobo Muñoz. Madrid: Trotta, 2002.

MARCUSE, H. Eros e civilização: uma interpretação filosófica do pensamento de Freud. Tradução de Álvaro Cabral. Rio de Janeiro: LTC, 1999.

NEME, C. Violência e segurança: um olhar sobre a França e o Brasil. Revista de Sociologia Política, Curitiba, n. 25, p. 123-137, nov. 2005.

NOAVES, A. (Org.). Civilização e barbárie. São Paulo: Companhia das Letras, 2004.

PINHEIRO, P. S.; ALMEIDA, G. A. de. Violência urbana. São Paulo: Publifolha, 2003.

ROUANET, S. P. Mal-estar na modernidade. São Paulo: Companhia das Letras, 1993.

Teoria crítica e psicanálise. Rio de Janeiro: Tempo Brasileiro, 1998.

. Adorno e a psicanálise. Revista Tempo Brasileiro, Adorno: 100 anos, Rio de Janeiro, n. 155, p. 131-156, 2003.

SCHRITZMEYER, A. L. P. Descrença nas instituições públicas de resolução de conflitos. Cidadania, verso $e$ reverso, São Paulo, Imprensa Oficial, p. 83-91, 1997.
UNIVERSIDADE DE SÃO PAULO. Terceiro Relatório Nacional sobre os Direitos Humanos no Brasil (2002-2005). Universidade de São Paulo: Núcleo de Estudos da Violência, 2007.

VALA, J.; MONTEIRO, M. B. (Coord.). Psicologia social. Lisboa: Fundação Calouste Gulbenkian, 2002.

WIGGERSHAUS, R. A Escola de Frankfurt: história, desenvolvimento teórico, significação política. Tradução de V. A. Harvey. Rio de Janeiro: DIFEL, 2002.

\section{Notas}

1 "Há também largas variações de país para país. Com taxa de 26,3 homicídios por 100 mil habitantes em 1999, o Brasil ocupa a segunda posição num conjunto de 60 países. Com referência à população jovem, o Brasil (taxa de 48,5 homicídios por 100 mil) ocupa o terceiro lugar, bem distante do grupo de países cujas taxas ficam abaixo de um homicídio por 100 mil jovens" (PINHEIRO; ALMEIDA, 2003,p. 18).

2 "O crescimento dos crimes e da violência no Brasil é, em grande medida, conseqüência da emergência e disseminação do crime organizado no Brasil, em especial em torno do tráfico de drogas, fenômeno intensificado a partir da década de 80 do século passado"(ADORNO, 2006,p. 08).

3 "Como vêm indicando vários estudos e pesquisas de opinião pública, o medo diante do crime constitui um dos quesitos principais ma agenda de inseguranças e incertezas do cidadão, em qualquer grande metrópole (Wright, 1987). Na sociedade brasileira, esse sentimento parece exacerbado diante da expectativa, cada vezmais provável, de qualquer um ser vítima de ofensa criminal. Em pesquisa realizada no Rio de Janeiro, observou-se que cerca de $30 \%$ dos entrevistados já haviam sido assaltados; $77 \%$ já tiveram algum morador de sua residência assaltado; $60 \%$ não confiam na justiça, proporção um pouco mais elevada (63\%) para a desconfiança na polícia (cf.Zaluar, 1989). Nessemesmo sentido, enquete realizada pela PNAD revelou que, no Brasil, do total de pessoas que se envolveram em conflitos criminais, $72 \%$ não se utilizaram da justiça para solução de seus problemas (IBGE-DEISO, 1990, v.1)" (ADORNO, 1999, p. 314-315).

4 “Apesar de a violência não ser o determinante em primeira instância da exclusão social, ela pode ser vista como expressão e conseqüência da nova realidade produzida pelo acirramento da competição social, das alterações dos valores morais e da nova lógica da sociabilidade que conforma uma sociedade de consumo, e também, em grande medida, pela incapacidade de o poder público reverter significativamente os indicadores da velha exclusão" (CAMPOS et al., 2003, p. 51). Também: "Os mapas da violência apresentam, comclareza, a correlação estreita entre a desigualdade social e a violência urbana"'(ENDO, 2005,p. 25). 
5 Perceba-se esta problemática pelos números: “Auto-infligida, interpessoal ou coletiva, a violência constitui um problema global de enormes dimensões. Em 1999, quase 1,7 milhão de pessoas foi intencionalmente morto por outras pessoas ou se suicidou, conforme o Relatório Mundial de Saúde de 2000. Nesse total, estima-se ter havido 520 mil homicídios, indicando um índice geral de 8,8 homicídios por 100 habitantes do planeta. Os homens foram responsáveis por $77 \%$ de todos esses homicídios, e seu índice (13,6 por 100 mil habitantes) representou mais de três vezes o das mulheres (quatro por 100 mil). Os maiores índices se concentraram entre homens na faixa etária dos 20 aos 44 anos (18,7 homicídios por 100 mil habitantes)"(PINHEIRO;ALMEIDA, 2003,p. 17).

6 "Vários autores (Caldeira, 2000; Murilo de Carvalho, 1987; Schwarcz, 1998; Adorno, 1996; Pinheiro, 1998; Fausto, 1984), no contexto da reflexão sobre a violência e cidadania no Brasil, grifaram a intrínseca relação entre os processos violentos do período escravocrata e as formas de violência no Brasil atual"(ENDO, 2005,p.27).

7 Daí o caráter circular da violência se instaurando no corpo social: "Não apenas com a dor impingida, mas, ao mesmo tempo, também com a dor sofrida. E pode fazê-lo num complexojogo com papéis reversíveis no qual o outro compõe um circuito que se retroalimenta de sua incrível unicidade e encerramento"(Ibid.,p.159).

8 'Advogar em nome da matança é a conseqüência 'natural' de quem se sente violado. A justiça será exigida, seja ela feita pelas instituições, seja feita com as próprias mãos, ou, ainda, com as mãos dos outros" (Ibid., p. 33).

9 “A concentração econômica crescente reduza grupos cada vez mais reduzidos os detentores do poder. Conglomerados econômicos cada vez mais gigantescos detêm parcelas cada vez maiores de autoridade real, reduzindo-se, na mesma proporção, o número de pessoas que controlam os processos societários.Arealidade da estratificaçãoétão visível queailusão da mobilidade se dissipa, por falta de qualquer fundamento objetivo capaz de dar plausibilidade ao mito.Aomesmo tempo, o capitalismo monopolista não consegue eliminar a irracionalidade inerente ao sistema. A crise e o desemprego assumem, cada vezmais, a forma de forças cegas, irredutíveis à ação consciente do homem. Nesse momento, o caráter sadomasoquista se torna dominante, enquanto expressão da nova etapa do capitalismo e exigência funcional de sua sobrevivência. Pois, quanto mais se agudizam as contradições dentro da sociedade..., quanto mais cegas e incontroláveis as forças sociais, quanto mais catástrofes como a guerra e o desemprego se impõem à existência individual como forcas fatídicas, tanto mais violenta e mais generalizada é a estrutura pulsional sadomasoquista, e portanto a estrutura caracteriológica autoritária, e tanto mais incondicional éa submissão do Destino, ao mesmo tempo virtude suprema e fonte de prazer. É esse prazer que permite ao homem suportar tal existência, e nesses termos o masoquismo revela-se como uma das condições psíquicas mais importantes para o funcionamento da sociedade, como um elemento essencial do cimento que assegura sua coesão"(ROUANET, 1998,p.57-58).

10 "Os levantamentos empíricos de Erich Fromm, então membro do Instituto, a estabelecer uma tipologia das diferentes modalidades de caráter - caráter sadomasoquista, revolucionário e ambivalente-e a postular a existência de uma correlação entre o caráter sadomasoquista e opiniões e tendências comportamentais autoritárias, tanto do ponto de vista das relações pessoais, quanto do ponto de vista das preferências políticas. Toda essa análise era feita na perspectiva freudiana”(ROUANET,2003,p. 142). Também: “Aaçãoe oato violento serão sempre, para a psicanálise freudiana, a expressão de muitos processos psíquicos complexos diferentes e complementares, como poderá ser muitas vezes desenvolvido nas reflexões sobre o sadomasoquismo. É a ele que Freud relegará o papel central na elucidação dos processos inconscientes que articulam a relação entre prazer psíquico, dore sexualidade"(ENDO, 2005,p. 151).

11 "Entre as várias possibilidades de expressão da pulsão de morte figuram expressões não-sexuais (dominação, destruição e vontade de poder) e outras sádico-masoquistas que aparecem como o exemplo do que Freud denomina de intrincação pulsional $\left(1923,1930,1933^{\mathrm{a}}\right)$, entre as pulsões sexuais e as pulsões de morte" (Ibid, p.208).

12 "Desse modo, cada vez mais é flagrante a ousadia no resgate de presos; a existência de áreas de grandes cidades onde prevalecem as regras ditadas pelo tráfico de drogas em detrimento da aplicação das leis; e a colonização de outros crimes como roubos a bancos, seqüestros, arrastões em apartamentos de luxo, clonagem de cartões de crédito, cujo recurso expropriado, convertido em moeda corrente, passa a alimentar o fluxo de caixa do crime-negócio" (ADORNO, 2006,p. 10).

13 Para um quadro mais completo do tema, leia-seAdorno(2006, p. 02): "Nesse contexto, a sociedade brasileira vem conhecendo crescimento das taxas de violência, nas suas mais distintas modalidades: crime comum, violência fatal conectada com o crime organizado, graves violações de direitos humanos, explosão de conflitos nas relações interpessoais e intersubjetivas."

14 "Em suma, no Brasil.e no mundo, o projeto civilizatório da modernidade entrou em colapso"(ROUANET, 1993, p. 09).

15 Freud adverte: "Susto (Schreck), medo (Furcht) e ansiedade (Angst) são palavras impropriamente empregadas como expressões sinônimas; são, de fato, capazes de uma distinção clara em sua relação com o perigo. A ansiedade descreve um estado particular de esperar o perigo ou preparar-se para ele, ainda que possa ser desconhecido. O medo exige um medo definido de que se tenha temor. Susto, contudo, é o nome que damos ao estado em que alguém fica, quando entrou em 
perigo sem estar preparado para ele, dando-se ênfase ao fator surpresa"(FREUD,1997, p. 23).

16 "De um lado, grupos de ação, que aceitam a fragmentação social imposta e convertem em instrumento. De outro, um sistema automatizado, sem lastro na deliberação racional da sociedade. Ambos partilhando o princípio de máximo efeito, com mínima participação social; vale dizer, oferecendo o mínimo alvo. Para o novo regime político, cuja psique parecia então nascer, propunha o nome de 'regime do atentado', uma vez que o princípio do atentado prevalecia dos dois lados, tanto nos atos de violência explícita, quanto na organização instrumental do processo de controle social e econômico"(HERRMANN, 2006,p.09).

17 "Paulatinamente vai se deixando a cidade, partindo para outras cidades, criando a sua própria, com blindagens, exércitos particulares e helicópteros, enclausurando-se nelas mesmas, localizadas em lugares inseguros etc.”(ENDO, 2005, p. 98).

18 "Regime do atentado: o sujeito dessa nova e terrível forma de psicopatologia das relações humanas não é evidentemente o terrorista ou o governo militarista desenvolvido, mas uma intrincada condição do homem contemporâneo, que envolve, entre outras coisas, um rebaixamento brutal do valor ontológico individual, em particular na periferia do mundo desenvolvido"(HERRMANN, 2006,p. 06).

19 "A imprevisibilidade, a surpresa, posam negativamente para o psiquismo diante do choque, e o choque advém e se constitui, podemos dizer, na articulação entre a percepção do perigo real vindo do exterior, e a percepção de um perigo interno que, de algum nodo, se articula ao primeiro, configurando a situação angustiante de perigo"(ENDO, 2005,p. 137).

20 "É uma população assustada, muitas vezes em pânico que, freqüentemente, não vê outra forma de combater a violência a não ser violentamente, apontando para um futuro catastrófico e potencialmente inviável para a cidade, repetindo ao infinito as possibilidades de qualquer cidadão, a qualquer tempo, ser violentado. Conviver com o traumático não deixa de ser uma forma de perpetuar as condições excessivas que possibilitam o trauma, de instaurar as condições subjetivas de sua reprodutibilidade, repetindo, como demonstrou Freud, compulsivamente, o que traumatiza e produz sofrimento. É também uma maneira de viver sob o princípio da sobrevivência, ancorado em formas sadomasoquistas, sádico-anais e pré-genitais, nas quais a busca do idêntico é perseguida como forma de reduzir ao mínimo a possibilidade do susto, do choque e do trauma, minorando as possibilidades traumatogênicas potencialmente presentes no encontro com o outro, o desconhecido, o diferente no contexto da cidade de São Paulo"(Ibid., p. 288).

21 "O que resta ao contrário, são presumíveis representações sintomáticas do excesso de meios, de potência excedente, levando à autodestruição. De modo geral, diria, o regime do atentado constitui a representação sintomática mais perfeita do trauma do fim do mundo. Aqui, é necessário ser preciso. O processo de gestação do regime do atentado tem sido lento e anterior ao trauma. Seu desencadeamento e conformação específica é que correspondem ao fenômeno traumático. O traumanão causa os fenômenos, só os conforma. Sendo ele mesmo já uma expressão de condições concretas preexistentes - nesse caso, do excesso de meios - o trauma molda a forma psíquica correspondente e a põe em movimento"(HERRMANN, 2006,p.20).

22 "Do mesmo modo, a repressão será diferente em escopo e grau, segundo a produção social seja orientada no sentido do consumo individual ou no lucro; segundo prevaleça uma economia de mercado ou uma economia planejada; segundo vigore a propriedade privada ou a coletiva. Essas diferenças afetam o próprio conteúdo do princípio da realidade, pois toda e qualquer forma do princípio de realidade deve estar consubstanciada num sistema de instituições e relações sociais, de leis e valores que transmitem e impõem a requerida modificação dos instintos. Esse corpo do princípio de realidade é diferente em diversos estágios da civilização" (MARCUSE, 1999,p. 52).

23 “A noção de uma civilização não-repressiva será examinada, não como uma especulação abstrata e utópica. Acreditamos que o exame está justificando com base em dois dados concretos e realistas: primeiro, a própria concepção teórica de Freud parece refutar a sua firme negação da possibilidade histórica de uma civilização não-repressiva; e, segundo, as próprias realizações da civilização repressiva parecem criar as precondições para a gradual abolição da repressão. Para elucidarmos esses dados, tentaremos reinterpretar a concepção teórica de Freud, segundo os termos de seu próprio conteúdo sócio-histórico"(Ibid., 1999, p.28).

24 Marcuse cita outros exemplos: "Por exemplo, as modificaçõese deflexõesdeenergia instintivanecessáriaà perpetuação dafamília patriarcal-monogâmica, ouauma divisãohierárquicado trabalho, ou ao controle público da existência privada do indivíduo, são exemplos de mais-repressão concernente às instituições e um determinado princípio derealidade"(Ibid., 1999,p.53).

25 “Aumentou sobremodo o fosso entre a evolução da criminalidade e da violência e a capacidade do estado de impor lei eordem"(ADORNO, 2006, p. 09).

26 "Se buscaram conferir uma feição modernizadora às políticas formuladas, agiram no interior de um quadro institucional conservador, dominando inclusive por atores que reivindicam o monopólio do saber técnico, não escutam especialistas fora de seus círculos corporativos, não se sujeitam à crítica externa, não prestam contas à sociedade, aos cidadãos eleitores de suas decisões e - o pior - não se sentem responsabilizados pelas conseqüências de suas ações"(Ibid., p. 06). 
27 "Esta fragmentação urbana nas primeiras décadas da República, francamente associada à especulação e aos interesses privados, demonstra a fraca definição do que é público, completamente associada, na capital paulista, ao interesse privado"(ENDO, 2005, p. 58).

28 "A ausência da justiça simplesmente engrossa o caldo da violência urbana, deixando a ação violenta como dispositivo a ser acionado a qualquer momento, como um patrimônio pessoal, privado, diante de uma justiça pública que tarda e falha"(Ibid.,p.103).

29 "O exercício da cidadania democrática torna-se dessa forma problemático, pois onde o exercício da liberdade é feito sem o concurso da razão, acaba sendo feito através da violência" (BARRETTO, 1992,p. 70).

30 'É isso que Freud voltará a abordar no informe sobre a eletroterapia dos neuróticos de guerra (1955) e o que voltará a fazer em Além do princípio do prazer (1920) e em Por que a guerra? (1933) vendo na pulsão de destruição, a expressão de uma força que se caracteriza por ignorar todos os esforços de ligação, representação e linguagem, ao mesmo tempo em que se dirige para um além da civilização, umalém do Eros, no qual a vida, enquanto laço, associação e sexualidade, terminaria"(ENDO, 2005, p. 119). "Habermas reagiu a esses problemas e a outros mais transformando o projeto de justificare de problematizar a teoria crítica da sociedade pela antropologia do conhecimento em um projeto de uma teoria crítica da sociedade que começaria pela teoria da comunicação. Tomando como ponto de partida o fato de que os homens falam e agem uns com os outros, ele tentava demonstrar que a antecipação de uma comunicação sem distorção era a condição para que uma ação comunicativa fosse possível - isto é, visando ao entendimento mútuo" (WIGGERSHAUS, 2002,p.671).

31 "Portanto, o ataque ao corpo é uma maneira de interromper a linguagem em seu princípio originário: o da mediação e da distância que se quer impor, que se pode impor. Violentar o corpo só atinge pleno êxito quando se alcança a dessubjetivação do sujeito, privando-o dos lugares onde ele se constitui"'(ENDO, 2005, p.92).

32 "O Eros incontrolado é tão funesto quanto a sua réplica fatal, o instinto de morte. Sua força destrutiva deriva do fato deles lutarem por uma gratificação que a cultura não pode consentir: agratificação como tal e comoum fimem si mesma, a qualquer momento. Portanto, os instintos têm de ser desviados de seus objetivos, inibidos em seus anseios. Acivilização começa quando o objetivo primário - isto é, a satisfação integral de necessidades - é abandonado" (MARCUSE, 1999, p. 33).

33 "Contudo voltando ao político, a violência desmedida dos próprios atentados terroristas, incluída a imolação do agente, é, em escala, uma reprodução bastante convincente, do Grande Atentado que continua suspenso sobre nossas cabeças e ativona psique social, assim como o são as medidas profiláticas e retaliatórias das potências militares. Digamos que se trata de 'suicídios coletivizados'. Em conjunto, e só em conjunto são compreensíveis, metaforizam pequenas guerras finais, uma atrás da outra"(HERRMANN, 2006, p. 21).

34 "Clausewitzafirmou, não semalgum cinismo, quea 'guerraéa continuação da política por outros meios', e seu dito tornouse lugar comum. A 'guerra que não houve', no entanto, tirou as coisas de seus lugares comuns. Porque ela está em curso, é a política de nosso tempo. Seria mais rigoroso, pois, concluir que a política tem sido continuação da guerra por outros meios, menos fragorosos, às vezes mais cruéis"(Ibid., 2006, p. 24).

\section{Eduardo C. B. Bittar}

Livre-Docente e Doutor em Direito pela Universidade de São Paulo (USP)

Professor Associado do Departamento de Filosofia e Teoria Geral do Direito da Faculdade de Direito da USP

Professor e pesquisador do Mestrado em Direitos Humanos do UniFIEO.

Pesquisador-Sênior do Núcleo de Estudos da Violência da USP (NEV-USP)

Presidente da Associação Nacional de Direitos Humanos (Andhep/ NEV-USP)

\section{NEV-USP}

Av. Professor Lúcio Martins Rodrigues

Travessa 4 - Bloco 2

Cidade Universitária

São Paulo - São Paulo

CEP: 05508-020 